\title{
New technology of medicine
}

The transformation of basic medical science has been a surprise to all of us, but especially to physicians.

LAST week's Nature conference in London was originally planned as one of a series. The intention was that the journal should continue in this vein with its traditional function of acting as a midwife between specialized laboratories and the wider audience outside. Experience has shown that there is a particular need of means by which people who used to be in academic life, but who are now elsewhere, in industry perhaps, may renew acquaintance at first hand with research. Most people were last week surprised that, no doubt more by luck than judgement, a meeting on the biotechnology of medicine appeared to coincide with the fruition of several threads of research in the field.

In retrospect, there is a surprise to be explained. In 1975, when the air was full of reports by government committees (and others) on the promise of biotechnology, the most common prediction was that the pharmaceutical industry would be quickly overwhelmed by a torrent of new products, artificially engineered versions of naturally occurring materials. And, to be sure, human insulin was quickly on the market, although not at such a price that it could hold off competition from chemically modified pig insulin. Since then have come human growth hormone, with an invaluable role to play in the treatment of disease, and the various interferons whose value has still to be defined. There remains a small army of biological materials still waiting in the wings, and there is no reason why the prospectuses of a decade ago will be found to have been bogus. But, inevitably, there is some disappointment in the air.

Much the same is true in the genetic manipulation of plants. Ten years ago, people talked endlessly of the transformation of agriculture that would come about when it proved possible to transplant nitrogen-fixing genes from leguminous plants to those that have evolved without them. There were even academic arguments on the esoteric question whether the effort would be worthwhile in temperate latitudes, where the intensity of sunlight is not enough to make full use of nitrogen-fixing genes. In reality, as events have shown, the nitrogen-fixing genes are a complex too large and well-tuned to be shifted easily from one plant to another. A better hope is that plants at present unable to fix nitrogen directly might, by engineering, be given the facility to form symbiotic associations with soil bacteria (see Jensen,
J.S., et al. Nature 321, 669; 1986). But that, too, will not happen the day after tomorrow, especially if modest agricultural experiments with engineered bacteria are held up for regulatory reasons.

None of this implies that last decade's promises on behalf of biotechnology were false. Did it not, after all, take more than a century to bring the steam engine from a dream to a reality? It is no shame that biotechnology has been required to mature. But the surprise is that so much has happened in medicine, in the treatment of patients, when these techniques were overshadowed by the hopes for new pharmaceuticals.

That monoclonal antibodies would be important has, of course been clear since the beginning, just eleven years ago. The principle that it is possible to make by this means a sensitive reagent for almost any antibody is well established now. But did you know that the more distant hope of coupling monoclonal antibodies to toxins so as to kill unwanted cells specifically is already in the early stages of clinical testing? That is what Professor Robert Baldwin (University of Nottingham) explained last week; among the unexpected findings so far is the discovery that the immune system can make antibodies against toxins when these are coupled to antibodies, which is a hurdle to be overcome. The notion that monoclonal antibodies can be used to sterilize the mouth and teeth against infection by streptococci (Professor Thomas Lehner, Guy's and St Thomas's, London) is another dream on the way to coming true.

Vaccines, the classical tools of preventive medicine, naturally featured in the prospectuses of the $1970 \mathrm{~s}$, but people had not then thought of the use of vaccinia virus as a means of showing antigens chosen at will to the human immune system. Although there were several at last week's meeting sharing the caution expressed by Dr Geoffrey Schild (director of the British National Institute for Biological Standards and Control) about the potential of vaccinia virus and an allpurpose antigenic vehicle, the plain fact is that this material, the several versions of malaria vaccine now being prepared for trials and the vaccines being worked up as prophylactics of schistosomiasis (Dr André Capron, Pasteur, Lille) would not have been possible without genetic manipulation.

Inevitably, AIDS (Acquired Immune
Deficiency Syndrome) crops up in these connections. Who can but be moved to recognize that an infection whose viral character was first demonstrated merely three years ago now has an agent described almost as fully as more or less any other virus? Dr Luc Montagier (Pasteur, Paris) gave such a telling account of this process of discovery last week, with due acknowledgement of the contributions of Gallo and his collaborators in the United States, that many in the audience must have come to share the view that it is a great misfortune that the French and US groups are now separated from each other by their patent suit.

Not surprisingly, AIDS brought into the open an issue lying beneath several of last week's talks. Montagnier had been talking about the rationale of a vaccine against AIDS, which is an awkward concept because it entails the stimulation of lymphocytes which, if already infected, will yield more virus. His chairman, Professor Avrion Mitcheson, raised (by means of a reference to the case of yellow fever) the question whether physicians in earlier days might not have been impelled to see whether a vaccine would cure one or two of their patients otherwise destined for a terminal infection. Earlier Schild had remarked, in passing, that it would have been hard to win regulatory approval for the Sabin live-virus vaccine against poliomyelitis. How great an encumbrance is the regulatory apparatus?

To be fair, nobody seems concerned to sweep away the system that has grown up to regulate the introduction of new pharmaceuticals, for example; what people ask for there is greater efficiency and a plainer understanding on legal implications. (Does licensing imply immunity from some legal suits?) The regulation of new research is more disturbing. Dr French Anderson (National Institutes of Health, Bethesda), describing preparations being made for work with human beings, acknowledged that the present system is probably a necessary way of giving the general public reassurance - even though it will entail a delay of at least six months between application and consent. Anderson is almost certainly right that the public and governments would not be satisfied with less. But how quickly will the apparatus be dismantled when it has served its purpose, and when there is a real danger that regulation will become an impediment to therapy?
John Maddox 